\title{
Sports Medicine and Indian Cricket: Exploring the Past, understanding the Present and accommodating a Future of Scientific Conception
}

\author{
${ }^{1}$ Harpal Kaur Bansal, ${ }^{2}$ Evan Speechly
}

\begin{abstract}
Background: 'What do they know of cricket who only cricket know?'-CLR James. Cricket is one of the oldest major international team sport, however, the integration of sports medicine research into the cricketing set-up has been relatively new. Cricketing nations, such as Australia, England and South Africa, have been at the forefront and have shown an increased interest to understand this game from a scientific point of view. On the contrary, in a country where cricket is like a religion it is sad to say that the lack of scientific rigor still echoes in the Indian dressing room. Nevertheless, a fresh approach brought in by foreign medical practitioners has planted the seed in local brains to bring the concept of sports medicine into the Indian cricketing fraternity.
\end{abstract}

Objectives: This article will explore scientific research that has been conducted on various areas in cricket and compare the role of sports science in Indian cricket and finally identify areas of future concern which would help to bridge the gap between sports medicine and Indian cricket.

Keywords: Cricket, India, Science.

How to cite this article: Bansal HK, Speechly E. Sports Medicine and Indian Cricket: Exploring the Past, understanding the Present and accommodating a Future of Scientific Conception. J Postgrad Med Edu Res 2015;49(4):199-203.

Source of support: Nil

Conflict of interest: None

\section{INTRODUCTION}

Cricket is one of the oldest international sport in modern history, played around the world for over eight centuries, yet scientific research into this sport has been sparse. One of the first studies which attempted to assess the average energy expenditure in cricket was conducted by Fletcher ${ }^{1}$ in 1955, who used a mathematical approach to estimate

\footnotetext{
${ }^{1,2}$ Physiotherapist

${ }^{1}$ Department of Physiotherapy, Thames River Physiotherapy Middlesex, United Kingdom

${ }^{2}$ Department of Physiotherapy, The Centre for Sports Medicine and Orthopaedics, Johannesburg, South Africa

Corresponding Author: Harpal Kaur Bansal, Physiotherapist Department of Physiotherapy, Thames River Physiotherapy Middlesex, United Kingdom, Phone: 02085747123, e-mail: hkbanz@yahoo.co.uk
}

that a test cricketer had an average energy expenditure of $650 \mathrm{~kJ}$ per hour depicting the game of cricket as an undemanding sport.

However, an increasing number of cricket research publications in sporting journals and the surging interest to understand the demands of the modern game from a scientific point of view has reduced the distance between the cricket field and the clinical laboratory. There have been a number of reviews on various aspects of the game, such as batting, ${ }^{2}$ fast bowling ${ }^{3}$ and physiological requirements of cricket $^{4}$ which have been generated from three major cricketing nations which are Australia, England and South Africa. Despite the attempts of a few individuals to view Indian cricket from a scientific perspective, there is still little to no clinically scientific research carried out in this cricket loving nation.

This article will aim to explore scientific research that has been conducted on various areas of cricket in three cricketing countries which are Australia, England and South Africa, and compare the role of sports science in Indian cricket and finally identify areas of future concern which would help to bridge the gap between sports medicine and Indian cricket.

\section{BACKGROUND}

Even though cricket is one of the world's oldest organized sports, the need to understand this game from a scientific point of view has been relatively new. The increased interest in sports medicine research over the past two decades has seen some ground-breaking publications in medical literature and has led to collaborations amongst several cricket playing nations which has resulted in some distinct joint international research projects.

One of the most vital area for cricket research has been the incorporation of injury surveillance as according to van Mechelen et $\mathrm{al}^{5}{ }^{5}$ ongoing injury surveillance is a fundamental pillar for successful injury prevention. The first ever consensus on international injury definitions in cricket was published in 2005 which was developed by Dr John Orchard and involved six nations working jointly to produce a generalized structure to report and record injury data. ${ }^{6}$ The Orchard Sports Injury Classification System (OSICS) is the world's most commonly 
used injury coding system in sports medicine ${ }^{7}$ and the most recent version is 10.1. ${ }^{7}$ After the generation of the consensus in 2005, there has been a renewed awareness among the sports medicine practitioners working within several cricketing set-ups at an elite level to record and report injury surveillance data which has allowed meaningful comparison of results from different countries and also across different time periods that has led to better identification of risk factors for injury profiles in cricket. ${ }^{6}$

Additionally, in the past decade, we have seen publications from South Africa, ${ }^{8}$ the English Cricket Board (ECB) including Ben Langley's injury surveillance work with the 18 first class county cricket squads over 5 years ${ }^{9}$ and the 4 years injury surveillance research with the England women's cricket squad. ${ }^{10}$ Moreover, from the subcontinent Stephen Mount's investigations with elite Sri Lankan cricket players helped put Sri Lanka on the global map of sports science research. ${ }^{11,12}$ To add on, Dr Akshai Mansingh's efforts facilitated to bring the concept of sports medicine in the West Indies dressing room through his injury surveillance work in 2006. ${ }^{13}$ Finally, for the first time a publication related to injury monitoring in Pakistan cricket was published in medical literature which included injury surveillance data as well as the impact of 2009 terrorist attacks on Pakistan cricket. $^{14}$

There has been research on several other aspects of the game of cricket and another piece of work that links science to this sport is the work of Christie $\mathrm{C}$ who analyzed the physiological demands of the game ${ }^{15,16}$ and her research findings have rebuked Fletcher's work ${ }^{1}$ proving that cricket is a physically demanding sport requiring players to be well trained. Furthermore, the introduction of Global Positioning System (GPS) monitoring over the last few years has allowed a greater understanding of the physical demands of the game and facilitates the conditioning coaches to develop individualized conditioning programs in order to enhance a player's fitness levels and improve their on-field performance. ${ }^{17,18}$

\section{SPORTS MEDICINE AND INDIAN CRICKET}

'What do they know of cricket who only cricket know?'19 CLR James posed this question when he examined the Caribbean society through the lens of cricket and the same can be relevant for the Indians too who were introduced to the game of cricket by their British Colonisers. In a country where cricket is like a religion and despite having legends bless the game, yet it is sad to say that the lack of scientific rigor still echoes in the Indian dressing room.

However, a new school of thought and a fresh approach brought in by foreign medical practitioners involved in the Indian Premier League (IPL) and in national squads has planted the seed in local brains to understand India's most popular team sport from a scientific point of view. There has been research at grassroot level on the incidence of upper limb injuries sustained by professional cricketers of North India ${ }^{20}$ cause of chronic low back pain in a young Indian fast bowler, ${ }^{21}$ exploring the connection between hand grip strength and anthropometric variables in district cricketers, ${ }^{22}$ examining the effects of sleeper's stretch on glenohumeral internal rotation and horizontal adduction range of movement in male elite cricket bowlers from Southern India ${ }^{23}$ and investigating the effect of body composition on $\mathrm{VO}_{2}$ max in under-19 and under-16 male cricket players. ${ }^{24}$

Additionally, research has been conducted on university level cricket players testing their physical fitness levels, ${ }^{25}$ investigating the correlation between back strength and leg strength ${ }^{26}$ and comparing the anxiety levels of male university cricket players across different universities during sporting competitions. ${ }^{27}$

Moreover, the establishment of Sri Ramachandra Arthroscopy and Sports Science Centre (SRASSC) in Chennai, which includes a three-dimensional (3D) motion analysis laboratory and has been accredited by the International Cricket Council (ICC) is a brilliant asset for the scientific development of Indian cricket. Some of the recent research projects that have emerged from this sports medicine center include, biomechanical analysis of cricket fast bowling in university cricket players which examined various technique factors such as, bowling action, shoulder counter-rotation, pelvic-shoulder separation angle, lateral flexion, front knee angle, front foot ground reaction force and ball release speed, ${ }^{28}$ and there was also a study conducted which compared the differences in bowling technique between young sub-elite (skilled) players and university level amateur cricketers. ${ }^{29}$ To add on, another research study compared twodimensional (2D) video analysis with 3D motion analysis to assess fast bowling action of Indian male university level fast bowlers. ${ }^{30}$

The concept of biomechanical analysis is still quite new to Indian cricket compared to other cricketing nations where there have been numerous research studies conducted over the past decade, such as Dr Rene Ferdinands' investigations which include the use of $3 \mathrm{D}$ motion analysis system to assess lumbar segment kinematics of fast bowlers, ${ }^{31}$ evaluating biomechanical measures of fast bowling to differentiate between legal and suspect bowling actions ${ }^{32}$ and more recently, examining the dynamics of spin bowling using a smart cricket ball and a cortex motion analysis system. ${ }^{33}$ Research on biomechanical aspects of the game of cricket in India is relatively new. Nevertheless, institutions, such as the 
SRASSC and the emergence of fresh ideas from individuals who hold a passion for sports medicine will help propel Indian cricket in the right direction and introduce new perspectives into the Indian cricketing set-up.

\section{EXPLORING INDIAN CRICKET: A DIFFERENT PERSPECTIVE}

The game of cricket is like a religion in India and the fascination with this sport has led to many interesting research studies on social and economic transformation of this game. There are articles analyzing Indian cricket's social history ${ }^{34}$ exploring the development of cricket as a postcolonial sport and how much the game has evolved since decolonization. ${ }^{35}$ Additionally, there has been intriguing work investigating the impact of India's on-field performance in international cricket matches on the Indian stock market and how performances of individuals within the team can have a detrimental effect on their respective leading stock indices. ${ }^{36}$

Moreover, in the past decade India has become the financial hub for cricket and one of the main factors that has steered the globalization of Indian cricket has been the IPL. ${ }^{37}$ However, there has also been resistance from traditionalists who have highlighted the potential dangers of its rapid success, high rewards and its susceptibility to corruption. ${ }^{38}$ Furthermore, research exploring the selection of cricket players using an analytical hierarchy process $^{39}$ and investigations on the influence of an individual's socioeconomic status on their chances of being selected at the national squad level ${ }^{40}$ illustrates that Indian cricket is still sunk in the conundrums of its colonial past.

\section{IMPORTANCE OF A SCIENTIFIC PERSPECTIVE IN INDIAN CRICKET: A RESEARCH PROPOSAL}

Despite the attempts of a few individuals to view Indian cricket from a scientific perspective, there is still a paucity of clinically significant scientific research. In a country where this game is thriving well financially, there has been little to no effort to incorporate science or embrace the concept that research in sport contributes to better performance. Cricket is a physically demanding sport therefore, a great area to investigate would be understanding the physical or physiological demands of the game at an elite level. Hence, this research proposal will bridge the gap between sports science and Indian cricket by exploring the fitness profiles of elite Indian male batsmen and elite Indian male bowlers. Recognizing the physical demands of cricket will lead to the development of scientific sound training programs for cricketers which will not only improve their performance but also prevent injuries allowing them to enjoy long and illustrious careers.

\section{AIM}

The purpose of the study is to compare the effect of a standardized cricket training program on the physiological and physical characteristics of elite cricket male bowlers with elite cricket male batsmen.

\section{Proposed Methodology}

To test the aforementioned aim, the proposed study will adopt a quantitative methodology and employ a differentsubject experimental research design. The population of interest for the study will consist of young male elite cricket players contracted to the Board of Control for Cricket in India (BCCI).

The study will be conducted on a 6 to 8 weeks period and players will be required to attend up to seven fitness testing sessions. The first session will involve recording of anthropometric characteristics and there will be a practice run of all the fitness tests. Thereafter, they will be tested on six separate occasions for a 6 weeks period. In the meantime, all the players will continue to train according to their standardized cricket training programs.

The first test will be McGill's trunk endurance test which consists of a series of tests that measure core muscle strength through four static trunk holds. The T-test is a simple fitness test which measures speed and agility and is a good predictor of a player's performance level. Finally, the Cooper's test will be used to assess a player's aerobic fitness and requires a player to run as far as possible in 12 minutes and the distance recorded will be used to calculate the $\mathrm{VO}_{2} \max [\mathrm{in} \mathrm{ml} / \mathrm{kg} / \mathrm{min}]$.

\section{DISCUSSION AND CONCLUSION}

The findings of this research will be directly applicable to elite international cricket players as well as domestic players too. The outcomes should provide coaches with evidential basis to develop individualized training programs and modify prescription of training drills to ensure that the training protocols match or exceed game demands. Moreover, international cricketers are exposed to greater demands imposed by the increasing number of matches per calendar year and thus are required to be in their peak physical condition at all times. Therefore, an understanding of the optimum fitness profile of a player will not only enhance performance but prevent injuries favoring the chances of an individual of being selected in a team.

Furthermore, this research will provide the local coaches, support staff and players with an insight into how the integration of science and sport can be utilized to improve performance and provide the basis of several interesting future projects, such as comparison of fitness profiles of Indian male cricketers with their female 
counterparts, explore the physical demands of the game between different formats or between training sessions and actual play.

In a country where science and cricket is a fairly new marriage this research study will bring the concept of sports and exercise medicine research into practice thereby raising the bar and introducing new perspectives into the Indian cricketing set-up.

\section{ACKNOWLEDGMENTS}

We thank Dr Alwar Thiagarajan (Sri Ramachandra Arthroscopy and Sports Sciences Centre, Chennai, Tamil Nadu, India), Patrick Farhart (Sports Physiotherapist/ Mentor), Dr David Raune (Clinical Psychologist/Project Advisor), Helen Bayne (Biomechanist/Project Advisor) and Dr Mandeep Dhillon for their help and support.

\section{REFERENCES}

1. Fletcher J. Calories and cricket. The Lancet 1955;265(6875): 1165-1166.

2. Stretch R, Bartlett R, Davids K. A review of batting in men's cricket. J Sports Sci 2000;18(12):931-949.

3. Elliott B. Back Injuries and the fast bowler in cricket. J Sports Sci 2000;8(12):983-991.

4. Noakes T, Durandt J. Physiological requirements of cricket. J Sports Sci 2000;18(12):919-929.

5. van Mechelen W, Hlobil H, Kemper H. Incidence, severity, aetiology and prevention of sports injuries: a review of concepts. Sports Med 1992;14(2):82-99.

6. Orchard JW, Newman D, Stretch R, Frost W, Mansingh A, Leipus A. Methods for injury surveillance in international cricket. British J Sports Med 2005;39(4):e22.

7. Orchard JW, Rae K, Brooks J, Hagglund M, Til L, Wales D, Wood T. Revision, uptake and coding issues related to the open access Orchard Sports Injury Classification System (OSICS) versions 8, 9 and 10.1. Open Access J Sports Med 2010;1: 207-214.

8. Stretch R, Bartlett R, Davids K. A review of batting in men's cricket. J Sports Sci 2000;18(12):931-949.

9. Langley B, Ranson C, Moore I. Five-year epidemiology of muscle injuries in professional cricket. In: Proceedings of the 5th World Congress of Science and Medicine in CricketWCSMC; 2015 March 23-27; Sydney (Australia); c2015. p59. [online]. Available at: http://cricketcongress2015.org/d/ WCSMC2015_abstract_book.pdf. [Accessed on 17 August 2015].

10. Langley B, Evans R, Ranson C. Four-year injury surveillance of an international women's cricket squad. In: Proceedings of the 5th World Congress of Science and Medicine in CricketWCSMC; 2015 March 23-27; Sydney (Australia); c2015. P60. [online]. Available at: http://cricketcongress2015.org/d/ WCSMC2015_abstract_book.pdf. [Accessed on 17 August 2015].

11. Mount S, Ranson C, Moore I. Three-year cricket injury surveillance: fast bowlers are the biggest injury burden. In: Proceedings of the 5th World Congress of Science and Medicine in Cricket-WCSMC; 2015 March 23-27; Sydney
(Australia); c2015. P72-73. [online]. Available at: http:// cricketcongress2015.org/d/WCSMC2015_abstract_book.pdf. [Accessed on 17 August 2015].

12. Mount S, Moore I, Ranson C. Bowlers are at greater risk of sustaining 'related', subsequent injuries than batters or wicket-keepers. In: Proceedings of the 5th World Congress of Science and Medicine in Cricket-WCSMC; 2015 March 23-27; Sydney (Australia); c2015. P74. [online]. Available at: http:// cricketcongress2015.org/d/WCSMC2015_abstract_book.pdf. [Accessed on 17 August 2015].

13. Mansingh A, Harper L, Headley S, King-MowattJ, Mansingh G. Injuries in West Indies Cricket 2003-2004. British J Sports Med 2000;40(2):119-123.

14. Orchard J, Khan HI, Khan HS, Khan AN, Khan ZI, Malik Y, Saleem S. Injury surveillance in Pakistan cricket and the impact of 2009 terrorist attack. In: Proceedings of the 5th World Congress of Science and Medicine in Cricket-WCSMC; 2015 March 23-27; Sydney (Australia); c2015. P85. [online]. Available at: http:/ / cricketcongress2015.org/d/WCSMC2015_abstract_book.pdf. [Accessed on 23 August 2015].

15. Christie C. The physical demands of batting and fast bowling during cricket. In: Zaslav KR (Editor). Sports Med Sports Injuries. 2012;InTech (ISBN 979-953-307-096-3).

16. Christie C, Todd A, King G. Selected physiological responses during batting in a simulated cricket work bout: a pilot study. J Sci Med Sport 2008;11(6):581-584.

17. Petersen C, Pyne D, Dawson B, Kellett A, Portus M. Comparison of training and game demands of National level cricketers. J Strength Cond Res 2011;25(5):1306-1311.

18. Petersen C, Pyne D, Portus M, Dawson B. Comparison of player movement patterns between 1 day and test cricket. J Strength Cond Res 2011;25(5):1368-1373.

19. James CLR. Beyond a boundary. London: Hutchinson; 1963.

20. Dhillon M, Garg B, Soni R, Dhillon H, Prabhakar S. Nature and incidence of upper limb injuries in professional cricket players a prospective observation. Sports Med, Arthroscopy, Rehabil, Therapy \& Technology 2012;4(1):42.

21. Bali K, Kumar V, Krishnan V, Meena D, Rawall S. Multiple lumbar transverse process stress fractures as a cause of chronic low back ache in a young fast bowler: a case report. Sports Med, Arthroscopy, Rehabil, Therapy \& Technology 2011;3(1):8.

22. Koley S, Yadav M. The relationship between hand grip strength and some anthropometric variables for Indian cricketers. Facta universitatis - series: physical education and sport 2009;7(2):113-123.

23. Gadkar H. Effect of sleeper's stretch on internal rotation and horizontal adduction range of motion in elite male cricket bowers. In: Proceedings of the 5th World Congress of Science and Medicine in Cricket-WCSMC; 2015 March 23-27; Sydney (Australia); c2015. P46. [online]. Available at: http:/ / cricketcongress2015.org/d/WCSMC2015_abstract_book.pdf. [Accessed on 23 August 2015].

24. Date A. Effect of body composition on $\mathrm{VO}_{2}$ max in under 16 and under 19 male cricket players. In: Proceedings of the 5th World Congress of Science and Medicine in Cricket-WCSMC; 2015 March 23-27; Sydney (Australia); c2015. P115. [online]. Available at: http:/ / cricketcongress2015.org/d/WCSMC2015_abstract_book.pdf. [Accessed on 23 August 2015].

25. Darshan D, Mehta D, Chandel S. Test of specific physical fitness of cricket players of Devi Ahilya University, Indore. Int J Sports Sci Fitness 2014;4(1):129-135. 
26. Koley S, Aseem K, Melton S. The correlation between back strength and leg strength for Indian cricketers from different universities. Facta universitatis—series: physical education and sport 2010;8(2):125-132.

27. Singh S. Sport competition anxiety among university level cricket players: a comparative study. Int J Res Pedagogy and Technol Education and movement Sci 2013;1(3):133-139.

28. Sayed A, Thiagarajan A, Gnanavel MB, Arumugam S. Biomechanical analysis of cricket fast bowling in university level bowlers in India. In: Proceedings of the 5th World Congress of Science and Medicine in Cricket-WCSMC; 2015 March 23-27; Sydney (Australia); c2015. P111. [online]. Available at: http:/ / cricketcongress2015.org/d/WCSMC2015_abstract_book.pdf. [Accessed on 23 August 2015].

29. Thiagarajan A, Sayed A, Gnanavel MB, Arumugam S. Comparison of cricket biomechanics factors in fast bowling between young league fast bowlers and amateur fast bowlers. In: Proceedings of the 5th World Congress of Science and Medicine in Cricket-WCSMC; 2015 March 23-27; Sydney (Australia); c2015. P104. [online]. Available at: http:// cricketcongress2015.org/d/WCSMC2015_abstract_book.pdf. [Accessed on 27 August 2015].

30. Parikh T, Unnithan S, Thiagarajan A, Sayed A, Arumugam S. Two-dimensional and 3D motion analysis of cricket fast bowling in India. In: Proceedings of the 5th World Congress of Science and Medicine in Cricket—WCSMC; 2015 March 23-27; Sydney (Australia); c2015. P113. [online]. Available at: http:/ / cricketcongress2015.org/d/WCSMC2015_abstract_book.pdf. [Accessed on 27 August 2015].
31. Ferdinands RED, Kersting U, Marshall RN. Three-dimensional lumbar segment kinematics of fast bowling in cricket. J Biomech 2009;42(11):1616-1621.

32. Ferdinands RED, Kersting U. An evaluation of biomechanical measures of bowling action legality in cricket. Sports Biomech 2007;6(3):315-333.

33. Fuss FK, Doljin B, Ferdinands RED, Beach A. Dynamics of spin bowling: the normalised precession of the spin axis analysed with a smart cricket ball. Procedia Eng 2015;112(2015): 196-201.

34. Naha S. The great tamasha: cricket, corruption and the turbulent rise of modern India. Int J Hist Sport 2015;32(2): 379-381.

35. Majumdar B. Nationalist romance to postcolonial sport: cricket in 2006 India. Sport in Society: Cultures, Commerce, Media, Politics 2007;10(1):88-100.

36. Mishra V, Smyth R. An examination of the impact of India's performance in 1 day cricket internationals on the Indian stock market. Pacific-Basin Finance J 2010;18(3):319-334.

37. Agur C. A Foreign Field No Longer: India, the IPL, and the Global Business of Cricket. J Asian Afr Stud 2013;48(5): 541-556.

38. Gupta A. The IPL and the Indian domination of global cricket. Sport in Society: Cultures, Commerce, Media, Politics 2011;14(10):1316-1325.

39. Kamble AG, Venkata Rao R, Kale A, Samant S. Selection of cricket players using analytical hierarchy process. Int J Sports Sci Eng 2011;5(4):207-212.

40. Majumdar B. Cricket in India: representative playing field to restrictive preserve. Culture, Sport, Society 2003;6(2-3):169-191. 